\title{
Description of a case of late-onset cryopyrin- associated periodic syndrome due to low-level somatic NLRP3 mosaicism
}

\author{
A Mensa-Vilaro', MT Bosque-Peralta², E Gonzalez-Roca', M Casorran-Berges², C Delgado-Beltran², S Plaza', \\ MC Anton', E Ruiz-Ortiz', J Yagüe', Jl Arostegui ${ }^{1 *}$ \\ From 8th International Congress of Familial Mediterranean Fever and Systemic Autoinflammatory Diseases \\ Dresden, Germany. 30 September - 3 October 2015
}

\section{Introduction}

Cryopyrin-associated periodic syndromes (CAPS) usually present in early childhood as an urticaria-like skin rash associated with an increased inflammatory response, with additional manifestations (i.e. arthropathy, AA amyloidosis or deafness) typically restricted to certain phenotypes. CAPS are caused by dominantly inherited or de novogain-of-functionNLRP3 mutations. The introduction of next-generation sequencing (NGS) into clinics has revealed the important role of somatic NLRP3 mosaicism in these syndromes by means of its detection in a high proportion of patients who were apparently mutation-negative by Sanger sequencing. Thus, NGS technologies are becoming essential for routinely identifying the genetic cause of the suspected autoinflammatory disease.

\section{Objective}

To describe a Spanish patient with CAPS that start in adulthood in whom molecular analyses detected a novel NLRP3 mutation as a somatic mutation.

\section{Patients and methods}

Genomic DNA was extracted from peripheral blood. The analysis of the six most common genes associated with autoinflammatory diseases (MEFV, TNFRSF1A, $M V K, N L R P 3, N O D 2$ and PSTPIP1) was performed by NGS. Additional molecular studies of somatic NLRP3 mosaicism were performed by targeted deep sequencing (TDS).

\section{Results}

The patient is a 63 year-old Spanish male who presented with a generalized urticarial rash, a gradually worsening oligoarthritis at wrists, elbows and knees, and a moderate bilateral sensorineural hypoacusia starting in his 50s. Laboratory results showed a marked leucocytosis, neutrophilia and increased inflammatory markers without evidence of circulating autoantibodies. Multiple therapeutic approaches including NSAID, corticosteroids, methotrexate and colchicine result in poor or partial responses. Screening of autoinflammatory-associated genes identified a novel NLRP3 variant (c.1906C>G; p. Gln636Glu) with an allele frequency of $12.2 \%$ (coverage: $738 x$ ). We hypothesized that this variant could be a somatic NLRP3 mutation. TDS confirmed the somatic NLRP3 mosaicism at 18.4 \% (mean of triplicates; mean coverage: $6225 \mathrm{x}$ ). Additional analyses showed that this variant has never been reported in public databases, that is located on a highly evolutionary conserved amino acid residue and that is predicted to be possibly damaging by PolyPhen-2 algorithm. Additional functional and genetic studies are currently ongoing.

\section{Conclusions}

We herein describe the case of a patient with a clinical picture compatible with MWS, with the exception of a late onset of the disease, who carries a somatic NLRP3 mosaicism. Our findings highlight the diagnostic utility of NGS technologies in detecting low-level somatic gene mosaicism and support its use as a routine genetic screening tool.

'Hospital Clínic, Immunology, Barcelona, Spain

Full list of author information is available at the end of the article 


\section{Consent to publish}

Written informed consent for publication of their clinical details was obtained from the patient/parent/guardian/ relative of the patient.

\section{Authors' details}

${ }^{1}$ Hospital Clínic, Immunology, Barcelona, Spain. ${ }^{2}$ Hospital Clinico Universitario Lozano Blesa, Zaragoza, Spain.

Published: 28 September 2015

doi:10.1186/1546-0096-13-S1-P60

Cite this article as: Mensa-Vilaro et al: Description of a case of late-

onset cryopyrin-associated periodic syndrome due to low-level somatic

NLRP3 mosaicism. Pediatric Rheumatology 2015 13(Suppl 1):P60.

Submit your next manuscript to BioMed Central and take full advantage of:

- Convenient online submission

- Thorough peer review

- No space constraints or color figure charges

- Immediate publication on acceptance

- Inclusion in PubMed, CAS, Scopus and Google Scholar

- Research which is freely available for redistribution

Submit your manuscript at www.biomedcentral.com/submit 